\title{
Gold and silver nanoparticles from Trianthema decandra: synthesis, characterization, and antimicrobial properties
}

This article was published in the following Dove Press journal:

International Journal of Nanomedicine

8 October 2012

Number of times this article has been viewed

\section{R Geethalakshmi \\ DVL Sarada}

Department of Biotechnology, School of Bioengineering, Sri Ramaswamy Memorial University, Kattankulathur, Tamil Nadu, India
Correspondence: DVL Sarada Department of Biotechnology, School of Bioengineering, Sri Ramaswamy Memorial University, Kattankulathur 603203, Tamil Nadu, India Email sarada.dvl@ktr.srmuniv.ac.in
Background: There is an increasing commercial demand for nanoparticles due to their wide applicability in various markets, including medicine, catalysis, electronics, chemistry, and energy. In this report, a simple and ecofriendly chemical reaction for the synthesis of gold and silver nanoparticles from Trianthema decandra (Aizoaceae) has been developed.

Methods and results: On treatment of aqueous solutions containing chloroauric acid or silver nitrate with root extract of $T$. decandra, stable gold or silver nanoparticles were rapidly formed. The kinetics of reduction of gold and silver ions during the reaction was analyzed by ultraviolet-visible spectroscopy. Field emission-scanning electron microscopy showed formation of gold nanoparticles in various shapes, including spherical, cubical, triangular, and hexagonal, while silver nanoparticles were spherical. The size of the gold nanoparticles was 33-65 nm and that of the silver nanoparticles was 36-74 nm. Energy dispersive x-ray and Fourier transform infrared spectroscopy confirmed the presence of metallic gold and metallic silver in the respective nanoparticles. The antimicrobial properties of the synthesized nanoparticles were analyzed using the Kirby-Bauer method. The results show varied susceptibility of microorganisms to the gold and silver nanoparticles.

Conclusion: It is believed that phytochemicals present in $T$. decandra extract reduce the silver and gold ions into metallic nanoparticles. This strategy reduces the cost of production and the environmental impact. The silver and gold nanoparticles formed showed strong activity against all microorganisms tested.

Keywords: Trianthema decandra, gold, silver, nanoparticles, antimicrobial activity

\section{Introduction}

Nanoparticles are a special group of materials with unique features and extensive applications in diverse fields. ${ }^{1}$ Metal nanoparticles, such as those containing gold and silver have recognized importance in chemistry, physics, and biology because of their unique optical, electrical, and photothermal properties. ${ }^{2}$ The ease of synthesizing gold and silver nanoparticles and their affinity for binding many biological molecules makes them attractive candidates for study. Various physical and chemical methods have been reported over the last two decades for the synthesis of gold and silver nanoparticles, of which chemical approaches, such as chemical reduction, electrochemical techniques, and photochemical reduction, are most widely used. The green method of nanoparticle synthesis employing plant extracts is a simple and viable alternative to chemical procedures and physical methods. ${ }^{3}$ Chemical and physical methods are harmful because the chemicals used are toxic, flammable, and are not disposed easily of in the environment. ${ }^{4}$ In recent years, biosynthesis of nanoparticles has received considerable attention due 
to the growing need to develop clean and nontoxic chemicals, environmentally friendly solvents, and renewable materials. ${ }^{5}$ Utilization of biological systems such as plant extracts for the synthesis of nanoparticles has advantages over chemical and physical methods, because these systems are cost-effective, environment friendly, single-step in nature, and easily scaled up for large-scale synthesis. ${ }^{6}$

Studies have shown that the size, morphology, stability, and physicochemical properties of metal nanoparticles are strongly influenced by the experimental conditions, ${ }^{7-9}$ and play pivotal roles in controlling the physical, chemical, optical, and electronic properties of these nanoscopic materials. This is particularly important for noble metals, such as gold and silver, which have strong surface plasmon resonance oscillations. ${ }^{10}$

Several researchers have reported the use of natural products, inactivated plant biomass, and as living plants such as Aloe vera, ${ }^{11}$ Carica papaya, ${ }^{12}$ Magnolia kobus, Diospyros kaki, ${ }^{13}$ Medicago sativa,${ }^{14,15}$ Azadirachta indica,${ }^{16}$ Pelargonium graveolens, ${ }^{17}$ Chilopsis linearis,${ }^{18}$ and Tamarindus indica ${ }^{19}$ for the production of silver and gold nanoparticles (Table 1). Large amounts of nanoparticles can be easily synthesized from plants, and the majority of these are nontoxic. They have been used in pharmaceutical drug-based industries for treating lymphocytic leukemia, detecting DNA, inhibiting bacteria and fungi, and preventing burns and open wound infections. ${ }^{20,21}$

Trianthema decandra, a prostrate, glabrous, succulent annual belonging to the Aizoaceae family, is found as a weed throughout most of India. ${ }^{22}$ The plant has various medicinal properties and has been reported to have antioxidant and antimicrobial properties. ${ }^{23}$ In the present study, we describe the biosynthesis of gold and silver nanoparticles from aqueous root extract of T. decandra for the first time. Chloroauric acid and silver nitrate were reduced to metallic gold and metallic silver respectively, on reaction with root extract of T. decandra, resulting in synthesis of gold and silver nanoparticles. The gold and silver nanoparticles formed were characterized using ultraviolet-visible, scanning electron microscopy, energy dispersive x-ray, and Fourier transform infrared spectroscopy. Antimicrobial assays using gold and silver nanoparticles demonstrated activity against all the microorganisms tested.

\section{Materials and methods Plant materials}

T. decandra L was collected from Salem district, Tamil Nadu, India, during June 2011. The plant was taxonomically identified and authenticated by the Botanical Survey of India, Coimbatore, and voucher specimen BSI/SRC/5/23/10-11/ Tech 975 was deposited at the Plant Biotechnology Laboratory, Sri Ramaswamy Memorial University, for future reference.

\section{Chemicals}

Gold (III) chloride trihydrate $\left(\mathrm{HAuCl}_{4}\right)$ and silver nitrate $\left(\mathrm{AgNO}_{3}\right)$ were purchased from Sigma-Aldrich, St Louis, MO. Double-distilled deionized water was used.

\section{Preparation of plant extracts}

Roots of $T$. decandra were washed with distilled water to remove dirt and soil. The shade-dried materials were powdered and passed through a 40-mesh sieve. Next, $20 \mathrm{~g}$ of coarsely powdered material was extracted with $100 \mathrm{~mL}$ of doubledistilled water. The mixture was filtered through Whatman No 1 filter paper. The extract was stored at $4^{\circ} \mathrm{C}$ until further use.

\section{Synthesis of gold and silver nanoparticles}

For the synthesis of gold and silver nanoparticles, $10 \mathrm{~mL}$ of $1 \mathrm{mM}$ aqueous $\mathrm{HAuCl}_{4}$ and $\mathrm{AgNO}_{3}$ solutions were separately added to $5 \mathrm{~mL}, 10 \mathrm{~mL}$, and $15 \mathrm{~mL}$ of aqueous root extract and incubated in the dark. The resulting colloidal solutions of gold and silver were then analyzed using ultraviolet-visible spectroscopy.

Table I Nanoparticles synthesized from different plants and their size range

\begin{tabular}{lllll}
\hline Number & Plant material used & Metal nanoparticle & Particle size (nm) & Reference \\
\hline 1 & Aloe vera & $\mathrm{Ag}$ and Au & 15.2 & 11 \\
2 & Carica papaya & $\mathrm{Ag}$ & $60-80$ & 12 \\
3 & Magnolia kobus & $\mathrm{Au}$ & $5-300$ & 13 \\
4 & Diospyros kaki & $\mathrm{Au}$ & $5-300$ & 13 \\
5 & Medicago sativa & $\mathrm{Ag}$ & $86-108$ & 14 \\
6 & Medicago sativa & $\mathrm{Au}$ & $15-200$ & 15 \\
7 & Azadirachta indica & $\mathrm{Ag}$ and Au & $50-100$ & 16 \\
8 & Pelargonium graveolens & $\mathrm{Au}$ & $21-70$ & 17 \\
9 & Chilopsis linearis & $\mathrm{Au}$ & 1.1 & 18 \\
10 & Tamarindus indica & $\mathrm{Au}$ & $20-40$ & 19 \\
\hline
\end{tabular}




\section{Ultraviolet-visible spectroscopy}

The colloidal solutions of gold and silver were diluted by adding $2.9 \mathrm{~mL}$ of deionized water to $0.1 \mathrm{~mL}$ of sample. Bioreduction of $\mathrm{HAuCl}_{4}$ and $\mathrm{AgNO}_{3}$ was recorded as a function of time using water as a reference at 3-hour intervals from zero hour up to 24 hours using an ultraviolet-visible spectrophotometer (Perkin-Elmer, Boston, MA) in a scanning range of $200 \mathrm{~nm}$ to $800 \mathrm{~nm}$.

\section{Purification of gold and silver nanoparticles}

To remove excess gold and silver ions, the gold and silver colloids were centrifuged at $10,000 \mathrm{rpm}$ for 15 minutes and washed at least three times with deionized water. A dried powder of the gold and silver nanoparticles was obtained by freeze-drying.

\section{Fourier transform infrared spectroscopy}

The air-dried powder form of the synthesized gold and silver nanoparticles was ground with $\mathrm{KBr}$ pellets and subjected to Fourier transform infrared spectroscopy.

\section{FE-SEM and energy dispersive x-ray spectroscopy}

The gold and silver nanoparticles formed were characterized using high resolution field emission scanning electron microscopy (FE-SEM). The samples were prepared by simple drop coating of the suspension of gold and silver nanoparticles separately on a carbon-coated copper grid, by simply dropping a very small amount of the sample on the grid, with excess solution removed using blotting paper. The film on the scanning electron microscopy grid was then allowed to dry under a mercury lamp for 5 minutes. Energy dispersive $\mathrm{X}$-ray spectroscopy was then performed using the Hitachi S-3400 N FE-SEM instrument equipped with a Thermo energy dispersive $\mathrm{x}$-ray spectroscopy attachment.

\section{Antimicrobial activity}

The antimicrobial activity of the gold and silver nanoparticles formed was assayed using the standard Kirby-Bauer disc diffusion method. ${ }^{24}$ Bacterial suspensions of Staphylococcus aureus (MTCC 29213), Streptococcus faecalis (MTCC 0459), Enterococcus faecalis (MTCC 2729), Escherichia coli (MTCC 443), Pseudomonas aeruginosa (MTCC 1035), Proteus vulgaris (MTCC 1771), Bacillus subtilis (MTCC 121), Yersinia enterocolitica (MTCC 840), and the fungus, Candida albicans (MTCC 183), grown overnight were swabbed on separate nutrient agar plates using L-rods. Whatman filter paper (No 1) discs $6 \mathrm{~mm}$ in diameter were

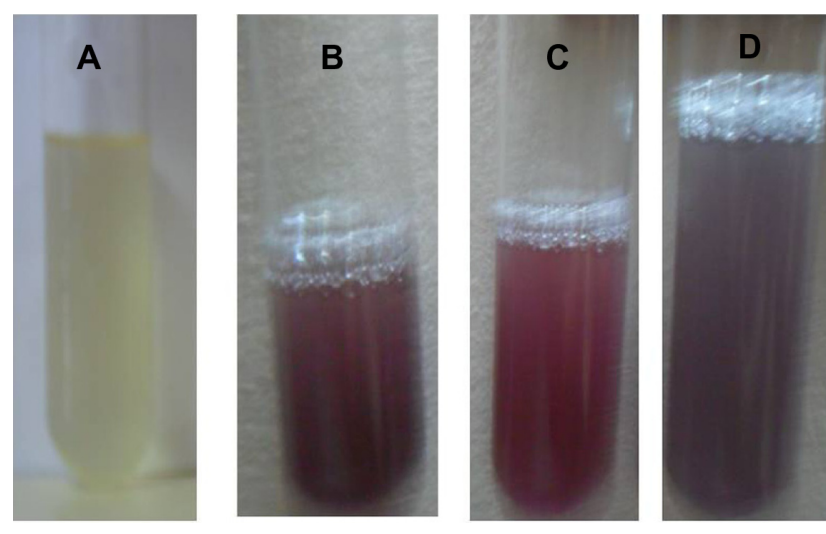

Figure I Optical photograph of colloidal solution of (A) Trianthema decandra root extract, (B) $\mathrm{HAuCl}_{4}$ solution reduced with $5 \mathrm{~mL}$ of $T$. decandra extract, (C) $\mathrm{HAuCl}_{4}$ solution reduced with $10 \mathrm{~mL}$ of $T$. decandra extract, and (D) $\mathrm{HAuCl}_{4}$ solution reduced with $15 \mathrm{~mL}$ of $T$. decandra extract.

separately impregnated with $20 \mu \mathrm{L}$ of a $10 \mathrm{mg} / \mathrm{mL}$ solution of gold and silver nanoparticles in dimethylsulfoxide. The discs were evaporated at $37^{\circ} \mathrm{C}$ for 24 hours and then impregnated on plates. Chloramphenicol and nystatin were used as positive controls for bacteria and the fungus respectively, while dimethylsulfoxide served as a negative control. Triplicates were maintained and the plates were incubated at $37^{\circ} \mathrm{C}$ for 24-48 hours. Diameters of the zones of inhibition were measured using a meter ruler, and the mean value for each organism was recorded and expressed in millimeters.

\section{Statistical analysis}

The data were analyzed by one-way analysis of variance followed by the Duncan's multiple range test.

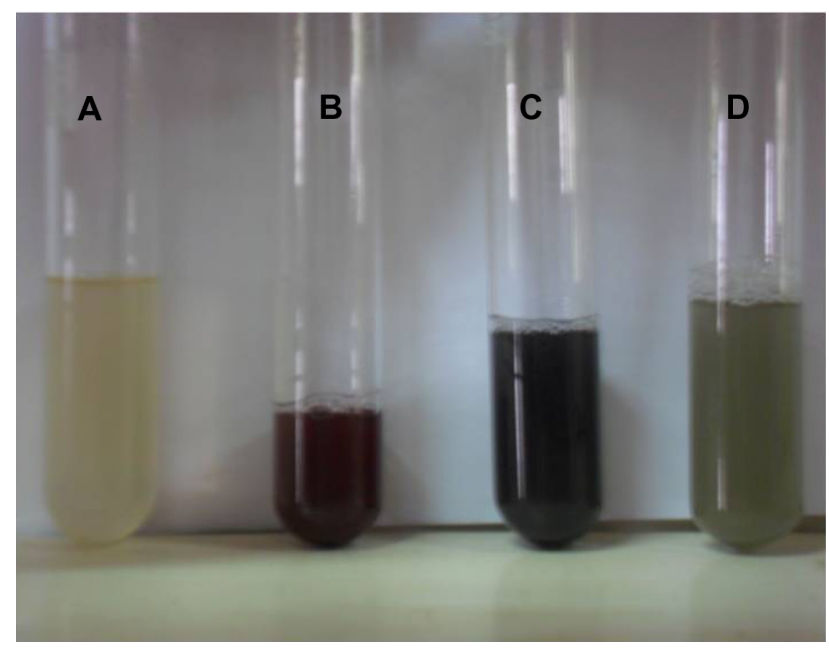

Figure 2 Optical photograph of colloidal solution of (A) Trianthema decandra root extract, (B) $\mathrm{AgNO}_{3}$ solution reduced with $5 \mathrm{~mL}$ of $T$. decandra extract, (C) $\mathrm{AgNO}_{3}$ solution reduced with $10 \mathrm{~mL}$ of $T$. decandra extract, and (D) $\mathrm{AgNO}_{3}$ solution reduced with $15 \mathrm{~mL}$ of $T$. decandra extract. 


\section{Results and discussion}

\section{Synthesis and characterization} of gold and silver nanoparticles

Nanoparticles of noble metals are characterized by the presence of bright colors produced by oscillations of the surface electron cloud of these particles. The formation of gold and silver nanoparticles was observed by monitoring the change in color, ie, a light yellow solution turning to ruby pink when $\mathrm{HAuCl}_{4}$ was used and a pale yellow solution
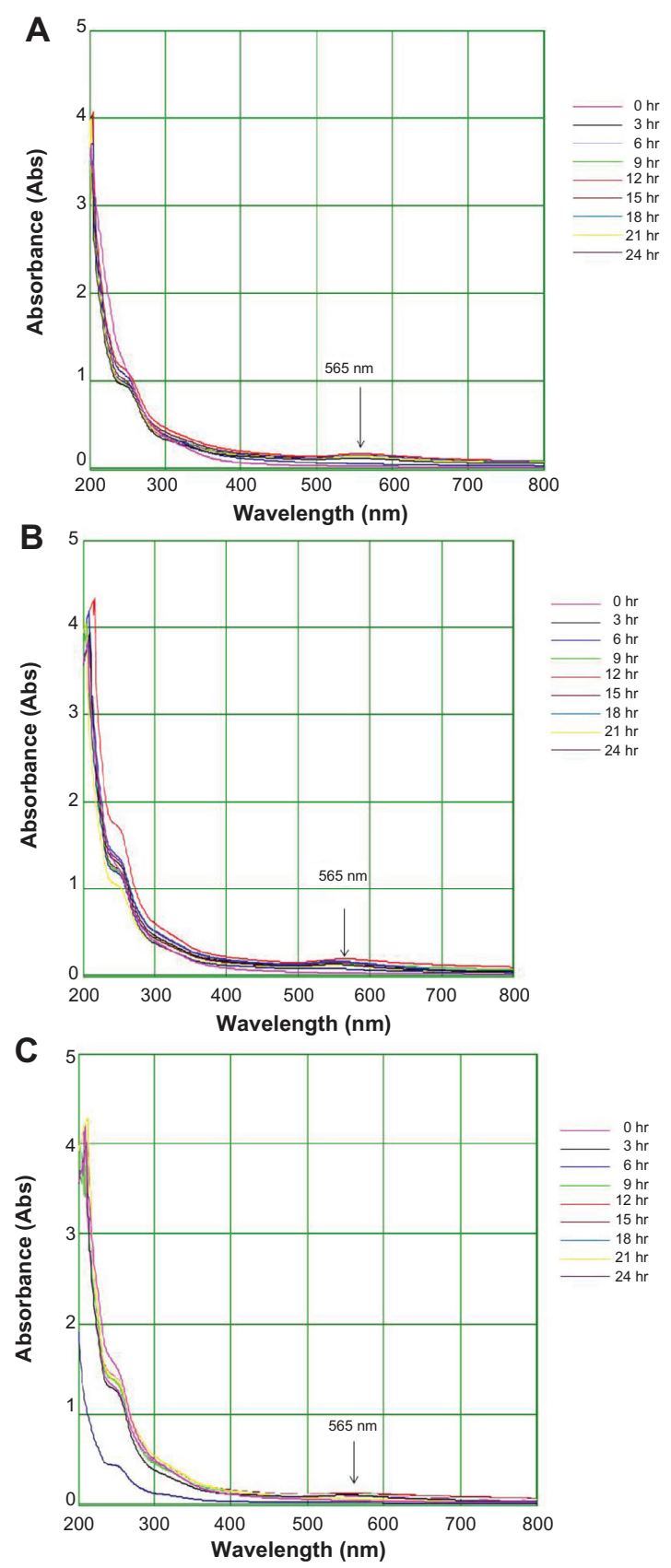

Figure 3 Ultraviolet-visible bioreduction kinetics in the 20-800 nm range for colloidal $\mathrm{HAuCl}_{4}$ solution with $5 \mathrm{~mL}$ of Trianthema decandra root extract (A), $10 \mathrm{~mL}$ of $T$. decandra root extract (B), and $15 \mathrm{~mL}$ of $T$. decandra root extract (C). turning to dark grey when $\mathrm{AgNO}_{3}$ was used. The collective oscillations of electrons in a nanoparticle upon interaction with light of suitable energy causes the nanoparticles to attain the color specific to a particular metal. Particle size, shape, and aggregation depend strongly on the frequency of oscillations..$^{25}$

The reduction kinetics of aqueous chloroaurate ions and silver ions leading to synthesis of gold and silver nanoparticles was compared using different amounts,
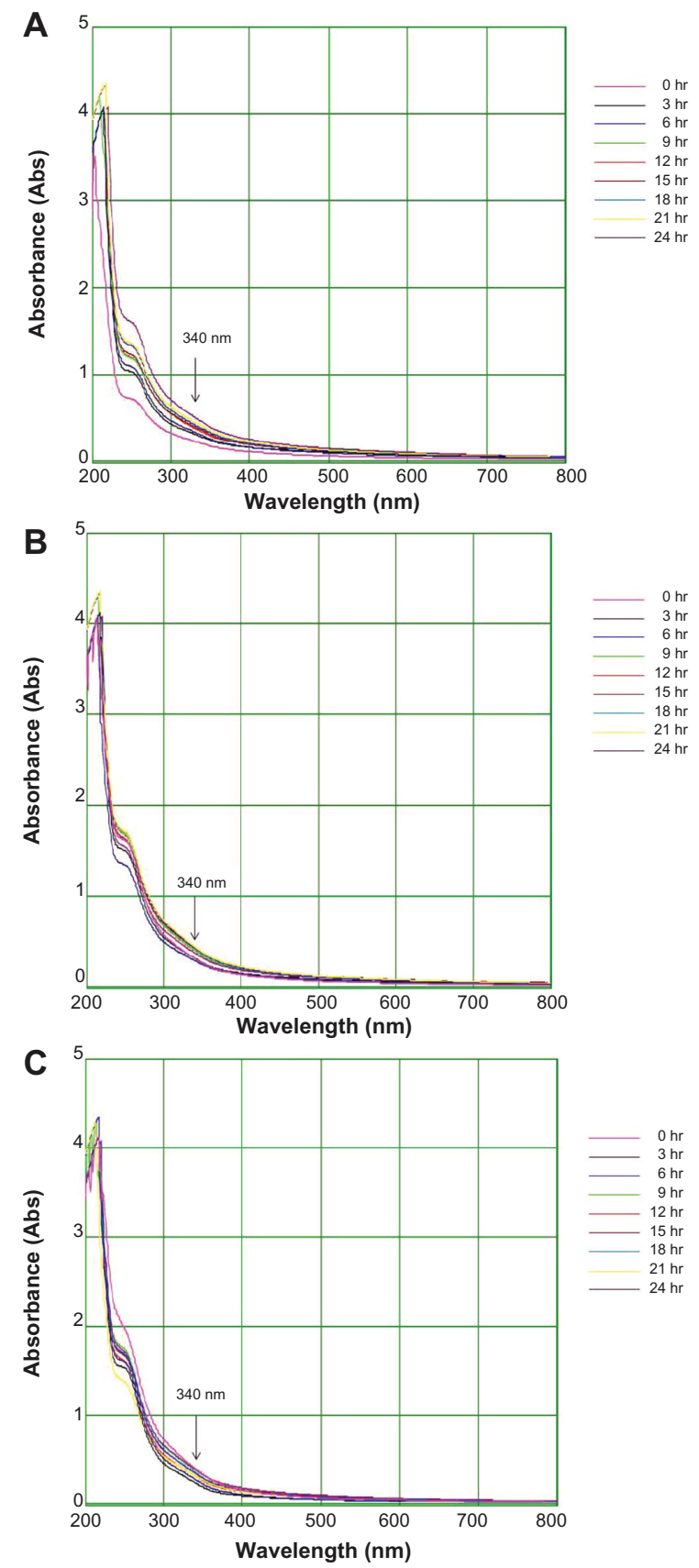

Figure 4 Ultraviolet-visible bioreduction kinetics in the $200-800 \mathrm{~nm}$ range for colloidal $\mathrm{AgNO}_{3}$ solution with $5 \mathrm{~mL}$ of Trianthema decandra root extract (A), $10 \mathrm{~mL}$ of $T$. decandra root extract (B), and $15 \mathrm{~mL}$ of $T$. decandra root extract (C). 
ie, $5 \mathrm{~mL}, 10 \mathrm{~mL}$, and $15 \mathrm{~mL}$ of root extract of $T$. decandra (Figures 1 and 2). Reduction of chloroaurate ions was more rapid than that of silver ions. Gold nanoparticles were synthesized within 3 hours of reaction with the root extract and the components thereof, while more than a 6-hour reaction period was required for synthesis of the silver counterpart. Preliminary phytochemical screening of aqueous extracts of $T$. decandra showed the presence of various secondary metabolites. ${ }^{26}$ The bioreduction achieved in the present study is attributed to the metabolites present in the plant. Synthesis of gold nanoparticles was pronounced when $15 \mathrm{~mL}$ of root extract was used for bioreduction, while $10 \mathrm{~mL}$ of the same root extract was sufficient for production of silver nanoparticles.

The colloidal gold solution showed strong (0.15 AU), weak (0.04 AU), and moderate (0.08 AU) absorption peaks with $15 \mathrm{~mL}, 5 \mathrm{~mL}$, and $10 \mathrm{~mL}$ of extract respectively, at $575 \mathrm{~nm}$ (Figure 3). The results also indicate a surface plasmon resonance gold band at $530-575 \mathrm{~nm}$. The colloidal silver solution showed strong (0.81 AU), weak (0.23 AU), and moderate (0.31 AU) absorbance peaks with $10 \mathrm{~mL}, 5 \mathrm{~mL}$, and $15 \mathrm{~mL}$ of extract respectively at $340 \mathrm{~nm}$ (Figure 4). Nanoparticles may grow in a process involving rapid bioreduction and strongly influence surface plasmon resonance in the water extract. ${ }^{27}$ The results of the present study are in accordance with previous reports, including that by Vijayakumar et $\mathrm{al}^{27}$ on Artemisia nilagirica, indicating occurrence of a silver band at 340-400 nm. Further characterization using Fourier transform infrared, scanning electron, and energy dispersive $\mathrm{x}$-ray spectroscopy was carried out for gold nanoparticles formed with $15 \mathrm{~mL}$ and silver nanoparticles formed with $10 \mathrm{~mL}$ of $T$. decandra root extract.

The functional groups present in gold nanoparticles detected using Fourier transform infrared spectroscopy had absorption peaks located at $1649.33 \mathrm{~cm}^{-1}$ and $1020.12 \mathrm{~cm}^{-1}$ in the region of $1000-1800 \mathrm{~cm}^{-1}$, characteristic of gold atoms (Figure 5). Two absorption peaks located at $1649.33 \mathrm{~cm}^{-1}$ and $1020 \mathrm{~cm}^{-1}$ are indicative of $\mathrm{C}=\mathrm{C}$ stretch and aromatic $\mathrm{C}-\mathrm{C}$ bonds, respectively. Distinct peaks in the range of $2344.87 \mathrm{~cm}^{-1}$ and $2364.35 \mathrm{~cm}^{-1}$ correspond to $\mathrm{C} \equiv \mathrm{N}$ stretch, while peaks at $2925.92 \mathrm{~cm}^{-1}$ and $3422.38 \mathrm{~cm}^{-1}$ correspond to $\mathrm{C}-\mathrm{H}$ and $\mathrm{O}-\mathrm{H}$ stretching vibration, respectively.

Fourier transform infrared spectroscopy analysis of the silver nanoparticles showed absorption peaks of reduced silver at $1653.96 \mathrm{~cm}^{-1}$ and $1027.44 \mathrm{~cm}^{-1}$ in the region of 1000-1800 $\mathrm{cm}^{-1}$ (Figure 6). Two absorption peaks located at $1653 \mathrm{~cm}^{-1}$ are associated with the stretch vibration of $\mathrm{C}=\mathrm{C}$, and the single absorbance peak located at $1027 \mathrm{~cm}^{-1}$ is assigned to $\mathrm{C}-\mathrm{N}$ stretching vibrations of amine. Further distinct peaks in the region of 2343.97-2362.27 $\mathrm{cm}^{-1}$ correspond to $\mathrm{C} \equiv \mathrm{N}$ stretch for nitrile groups, while $3447.86 \mathrm{~cm}^{-1}$ corresponds to $\mathrm{O}-\mathrm{H}$ stretching vibration.

Scanning electron micrographs (Figure 7) for the gold nanoparticles reveal numerous spherical, triangular, hexagonal, and cubic structures produced by reduction of goldions with sizes ranging between $33.7 \mathrm{~nm}$ and $99.3 \mathrm{~nm}$.

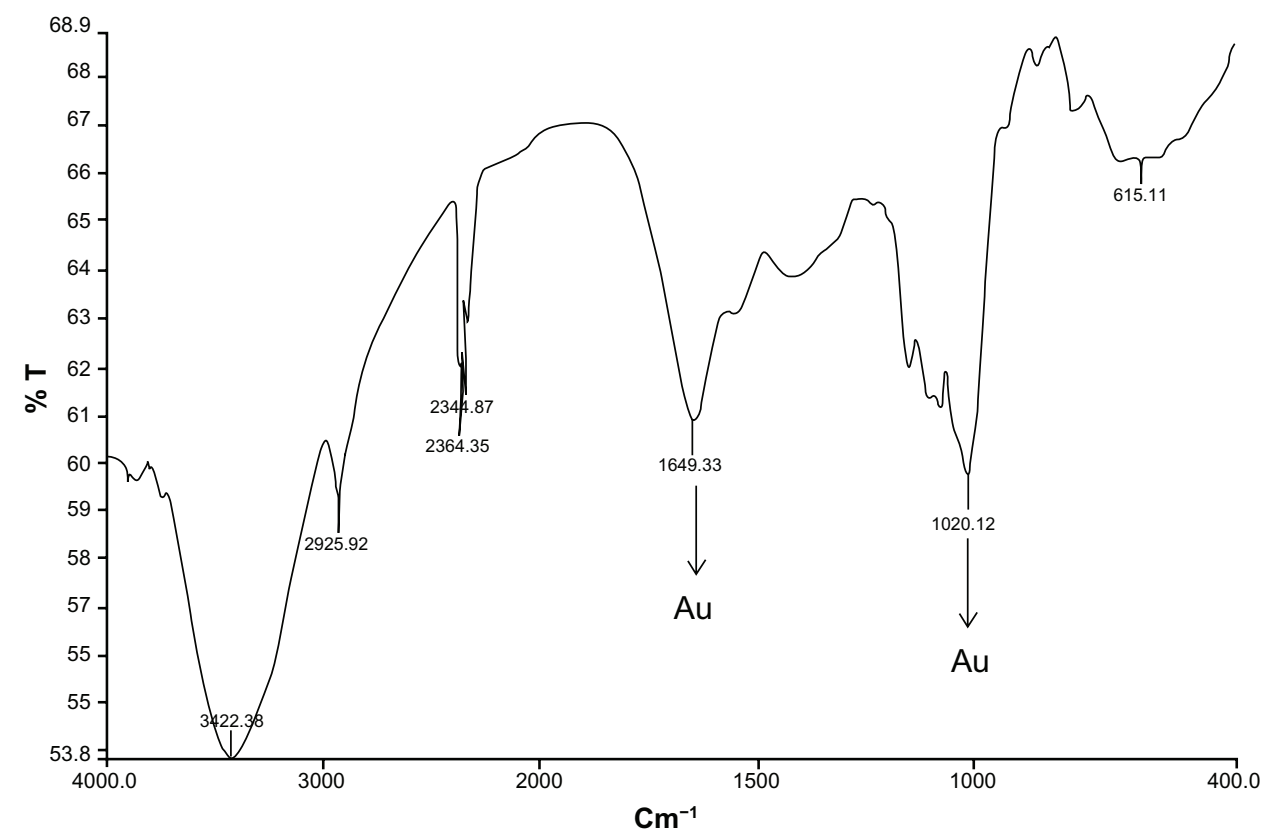

Figure 5 Fourier transform infrared absorption spectra for nanoparticles synthesized by bioreduction of $\mathrm{HAuCl}_{4}$ ions using Trianthema decandra root extract. 


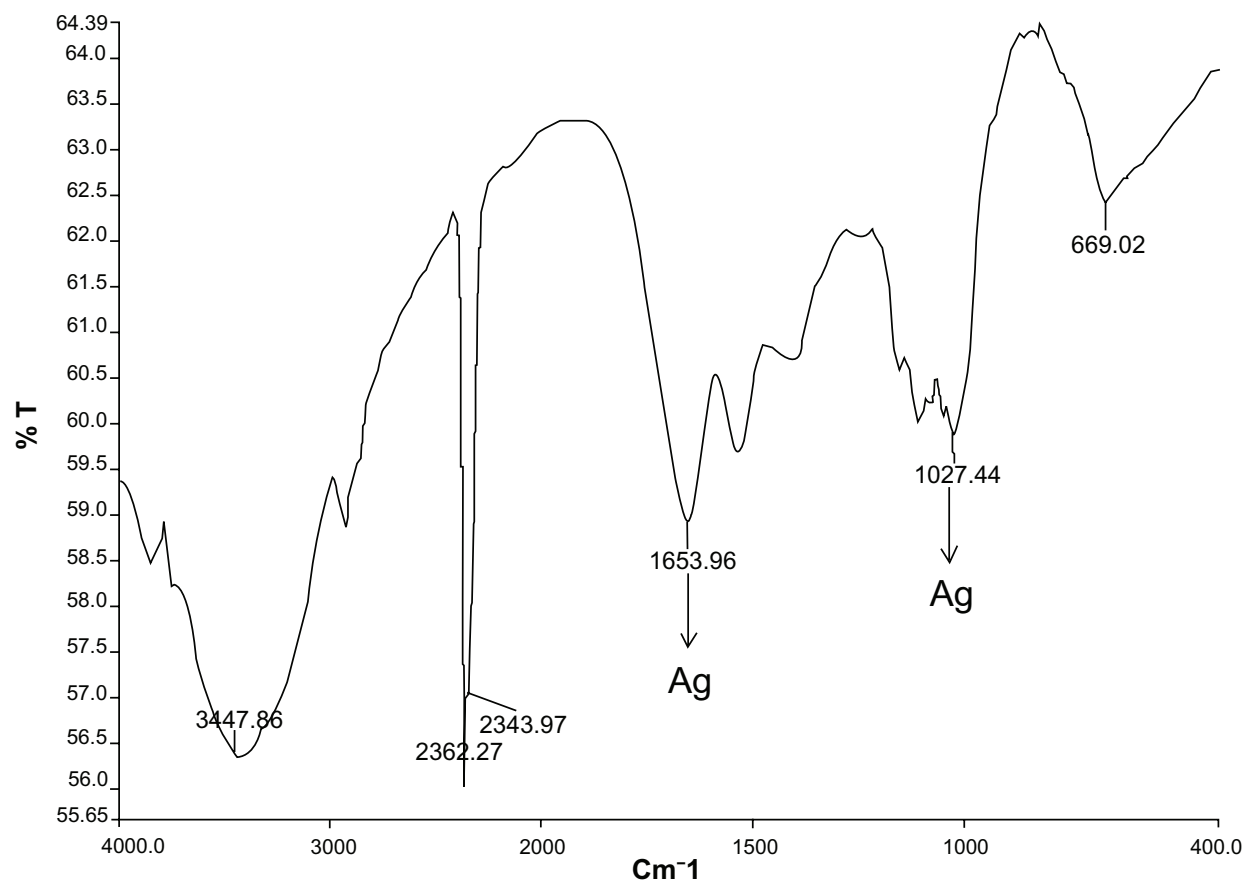

Figure 6 Fourier transform infrared absorption spectra for nanoparticles synthesized by bioreduction of $\mathrm{AgNO}_{3}$ ions using Trianthema decandra root extract.
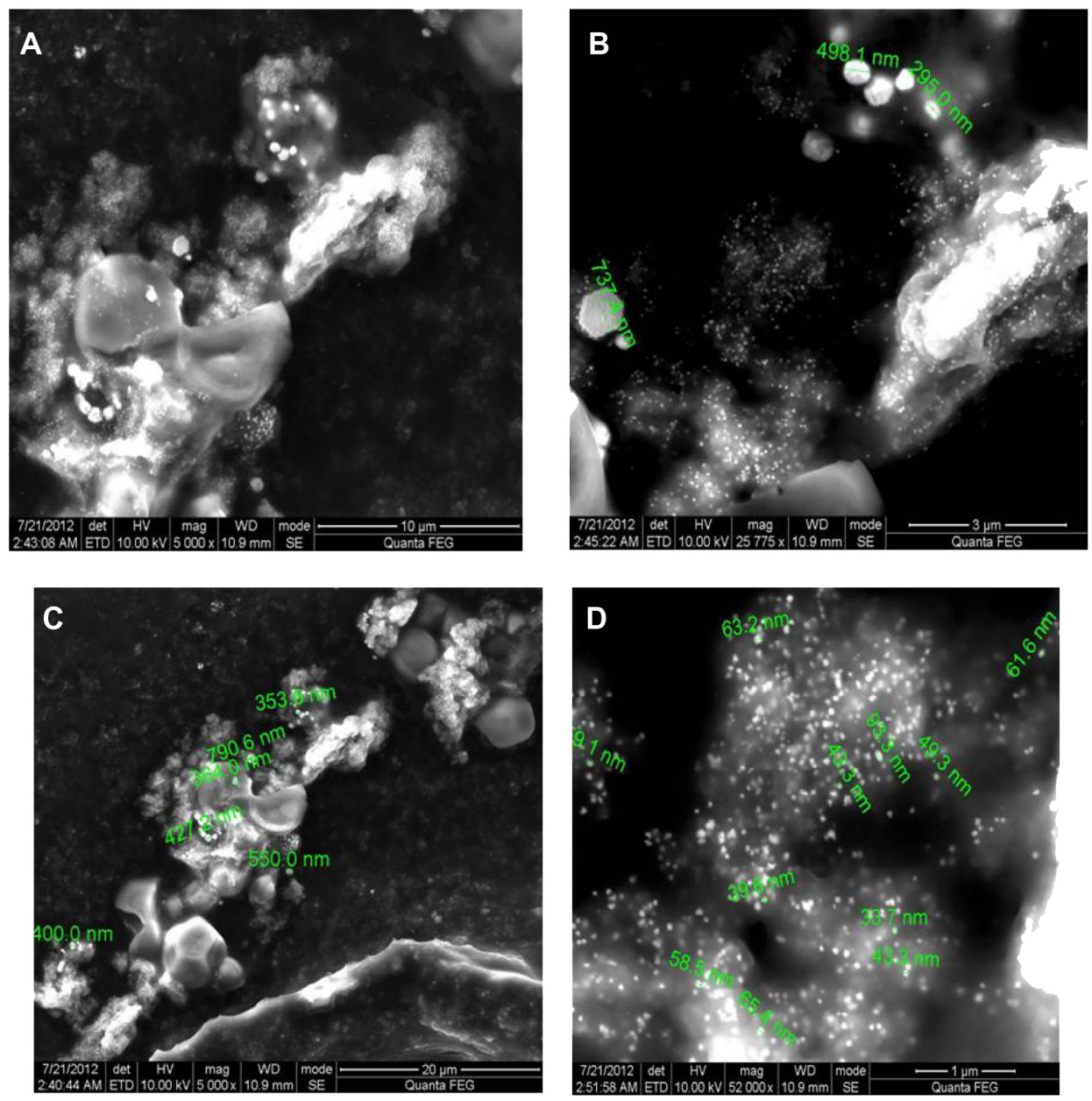

Figure 7 Scanning electron micrographs of gold nanoparticles observed from the reaction of $\mathrm{Au}^{3+}$ cations with Trianthema decandra root extract. 

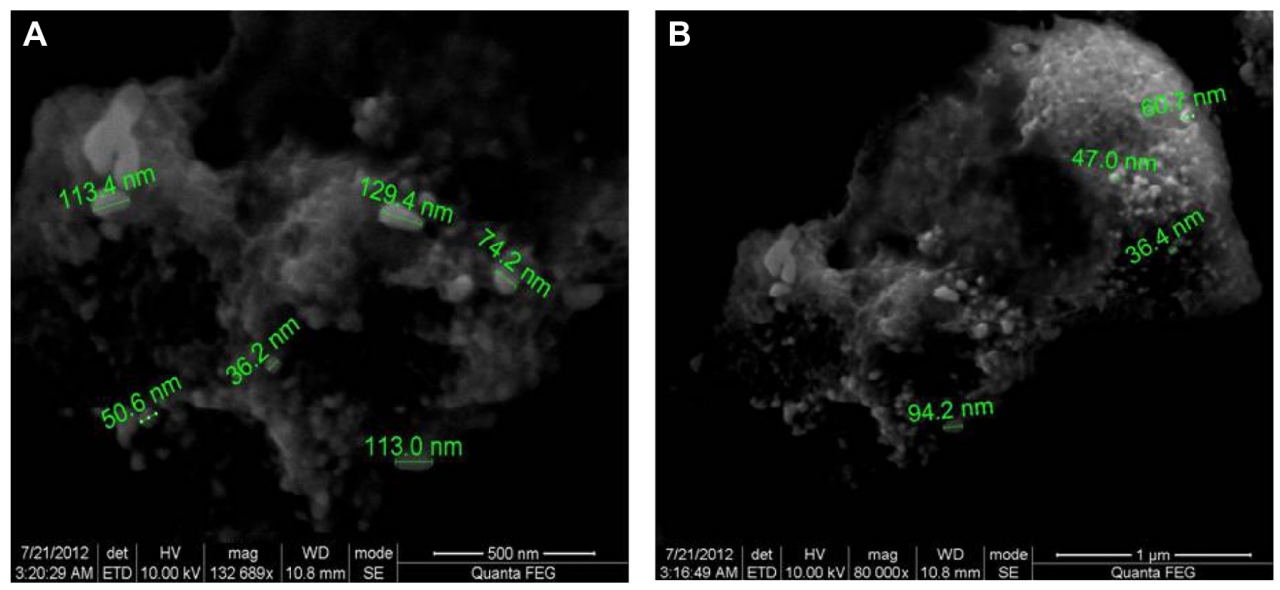

Figure 8 Scanning electron micrographs of silver nanoparticles observed from reaction of $\mathrm{Ag}^{+}$cations with Trianthema decandra root extract.

An individual gold nanohexagon with an average edge length of $737 \mathrm{~nm}$ is also seen in Figure 7B.

Very recently, Rai et al have demonstrated that the presence of halide ions and modulation of temperature can control the morphology of biologically synthesized gold triangles using lemongrass leaf extract. ${ }^{28}$ In the present study, nanoparticles resembling triangles with sizes ranging between $33.7 \mathrm{~nm}$ and $99.3 \mathrm{~nm}$ were produced during bioreduction of $\mathrm{HAuCl}_{4}$, which could be attributed to the chloride ions present in it (Figure 7D).

Spherical silver nanoparticles with diameters of 36-94 nm are depicted in the scanning electron micrographs (Figure 8). The variation in particle sizes, such as 36, 47, 60, and $94 \mathrm{~nm}$, is possibly due to the fact that the nanoparticles are being formed at different times.

Water-soluble heterocyclic compounds, including saponin, were mainly responsible for the reduction of silver ions or chloroaurate ions to metallic silver and metallic gold, respectively. Further, it has been shown that the presence of chloride ions during nanosynthesis promotes the growth of nanotriangles. In the present study, reduction of chloroaurate ions produced nanotriangles. The presence of gold atoms in the gold nanoparticles was further confirmed by energy dispersive $\mathrm{x}$-ray spectroscopy. The optical absorption peak was observed at approximately $2.2 \mathrm{keV}$, which is typical of gold nanocrystallite absorption due to surface plasmon resonance. The current energy dispersive $\mathrm{x}$-ray spectroscopic profile of gold nanoparticles of $T$. decandra (Figure 9) showed strong gold atom signals around 0.30, 2, 2.2, 2.4, and 9.7 $\mathrm{keV}$. Similarly, the presence of silver atoms in the silver nanoparticles was confirmed using energy dispersive $\mathrm{x}$-ray spectroscopy (Figure 10). The optical absorption peak was observed at $3 \mathrm{keV}$, which is typical for silver nanocrystallite absorption due to surface plasmon resonance. In an earlier study, individual spherical silver nanoparticles synthesized using alfalfa showed absorption peaks in the range of 2.5-4 keV. ${ }^{29}$ The current profile of energy dispersive $\mathrm{x}$-ray spectroscopy for silver nanoparticles of $T$. decandra indicate strong silver atom signals around $0.20,3,3.2$, and $3.4 \mathrm{keV}$.

\section{Antimicrobial activity of gold and silver nanoparticles}

Antimicrobial activity of the synthesized gold and silver nanoparticles was studied using eight different bacteria, namely $S$. aureus, $S$. faecalis, E. faecalis, E. coli, P. aeruginosa, P. vulgaris, B. subtilis, $Y$. enterocolitica, and a fungus, $C$. albicans.

Both gold and silver nanoparticles exhibited excellent activity against $Y$. enterocolitica, $P$. vulgaris, E. coli, S. aureus, and S. faecalis. Zones of inhibition measuring $13.5-15.5 \mathrm{~mm}$

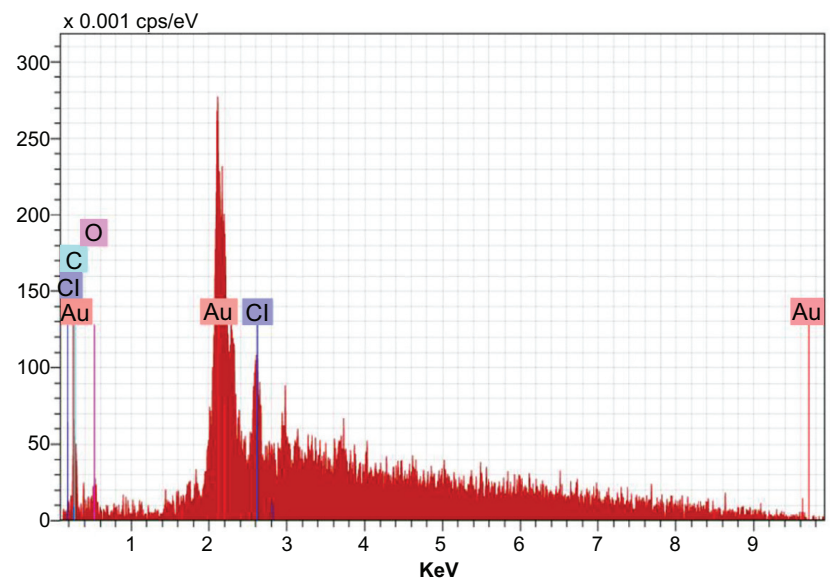

Figure 9 Energy dispersive x-ray spectroscopy of gold nanoparticles synthesized by Trianthema decandra root extract. 


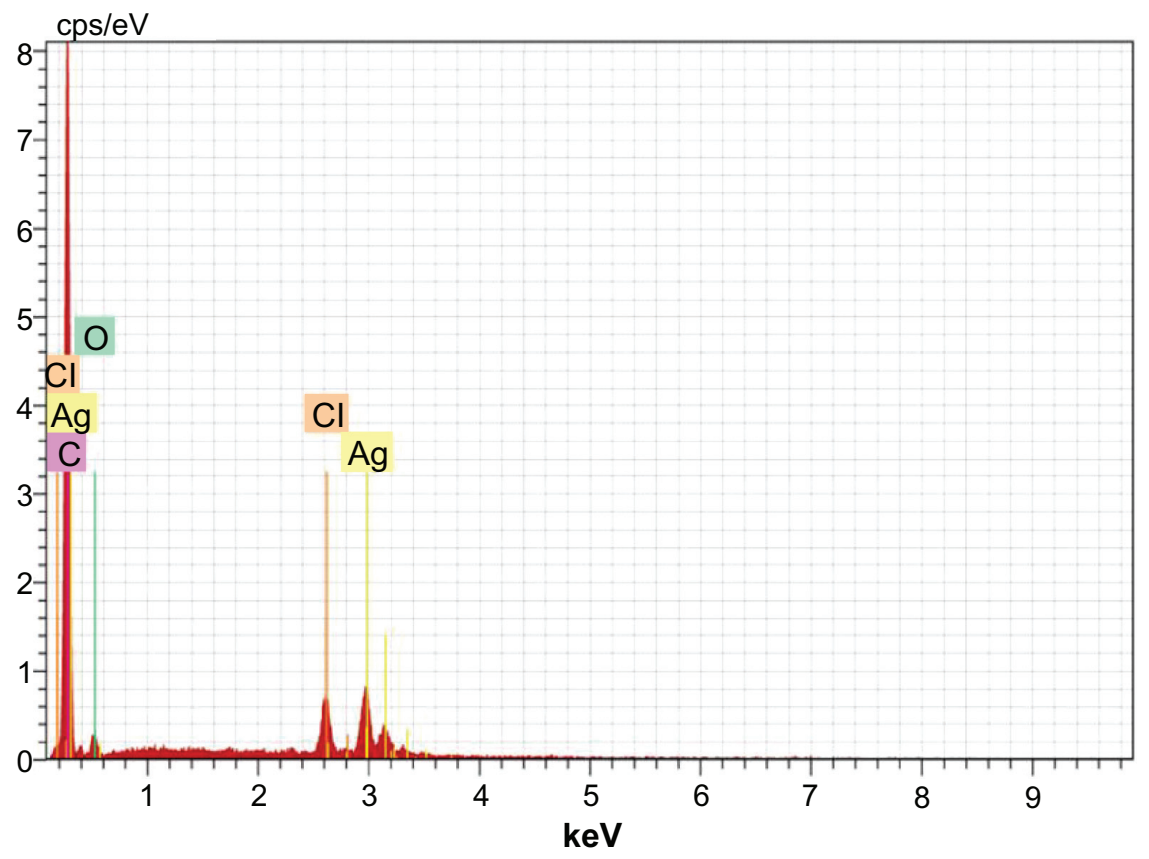

Figure 10 Energy dispersive x-ray spectroscopy of silver nanoparticles synthesized by Trianthema decandra root extract.

were recorded for the gold nanoparticles, while their silver counterparts recorded zones of 15.5-20.5 mm. Moderate activity was recorded against the other three bacteria tested (Table 2, Figures 11 and 12). The growth inhibition of C. albicans was double in silver nanoparticles when compared with gold nanoparticles. The antibacterial effect was more pronounced in Gram-negative bacteria than Gram-positive ones. The antimicrobial activity of colloidal silver particles is influenced by the particle dimensions. ${ }^{30}$ Silver has long been recognized as having an inhibitory effect on microbes present in medical and industrial processes. The most important application of silver and silver nanoparticles is in medical industry, such as in topical ointments to prevent infection against burns and open wounds. ${ }^{31}$ Gold nanoparticles are harmful to bacteria and fungi. They bind closely to the surface of microorganisms, causing visible damage to cells, with complete destruction of flagella, stimulated production of biofilm, and aggregation within the biofilm. ${ }^{32}$

Comparison of gold and silver nanoparticle sizes indicates the latter to be smaller than the former. We attribute the higher activity of silver nanoparticles to their small size. The smaller particles have greater antimicrobial effects. ${ }^{33}$ Further, the antimicrobial activity in the present study was much higher when compared with previous reports. Silver nanoparticles from Polyalthia longifolia, Balsamodendron mukul, Melia azadirachta, Berberis aristata, Acorus calamus,

Table 2 Mean zone of inhibition of synthesized gold and silver nanoparticles from T. decandra

\begin{tabular}{|c|c|c|c|c|c|}
\hline & AuNPs & AgNPs & $\begin{array}{l}\text { Positive } \\
\text { control }\end{array}$ & $\begin{array}{l}\text { Negative } \\
\text { control }\end{array}$ & $\begin{array}{l}\text { Water } \\
\text { extract }^{23}\end{array}$ \\
\hline \multicolumn{6}{|c|}{ Diameter of zone of inhibition ( $\mathrm{mm}$ ) } \\
\hline Enterococcus faecalis & $10.5 \pm 0.7^{c}$ & $14.0 \pm 1.4^{b}$ & $19.5 \pm 0.7^{\mathrm{a}}$ & - & - \\
\hline Staphylococcus aureus & $14.5 \pm 0.7^{b}$ & $13.5 \pm 0.7^{b}$ & $29.0 \pm 0.7^{a}$ & - & - \\
\hline Streptococcus faecalis & $13.5 \pm 0.7^{c}$ & $15.5 \pm 0.7^{b}$ & $19.5 \pm 0.7^{a}$ & - & - \\
\hline Bacillus subtilis & $9.5 \pm 0.7^{c}$ & $12.0 \pm 1.4^{b}$ & $25.5 \pm 0.7^{\mathrm{a}}$ & - & $2 \pm 0.7^{d}$ \\
\hline Yersinia enterocolitica & $15.5 \pm 0.7^{c}$ & $17.5 \pm 0.7^{\mathrm{b}}$ & $29.0 \pm 1.4^{\mathrm{a}}$ & - & $3 \pm 0.7^{d}$ \\
\hline Proteus vulgaris & $15.0 \pm 1.4^{\mathrm{c}}$ & $20.5 \pm 0.7^{b}$ & $25.0 \pm 1.4^{\mathrm{a}}$ & - & $3 \pm 0.7^{d}$ \\
\hline Escherichia coli & $9.5 \pm 0.7^{c}$ & $15.5 \pm 0.7^{b}$ & $25.5 \pm 0.7^{\mathrm{a}}$ & - & $4 \pm 0.7^{d}$ \\
\hline Pseudomonas aeruginosa & $11.5 \pm 0.7^{c}$ & $14.5 \pm 0.7^{b}$ & $27.5 \pm 0.7^{\mathrm{a}}$ & - & $3 \pm 0.7^{d}$ \\
\hline Candida albicans & $8.5 \pm 0.7^{c}$ & $14.5 \pm 0.7^{b}$ & $22.5 \pm 0.7^{\mathrm{a}}$ & - & $2 \pm 0.7^{d}$ \\
\hline
\end{tabular}

Notes: Values are expressed as the mean \pm standard error of the mean $(n=3)$, and values followed by same letter are not significantly different at the $P<0.05$ as determined by the Duncan's multiple range test. Positive control was chloramphenicol/nystatin; negative control was dimethyl sulfoxide; -, indicates no inhibition. Abbreviations: AuNPs, gold nanoparticles; AgNPs, silver nanoparticles. 


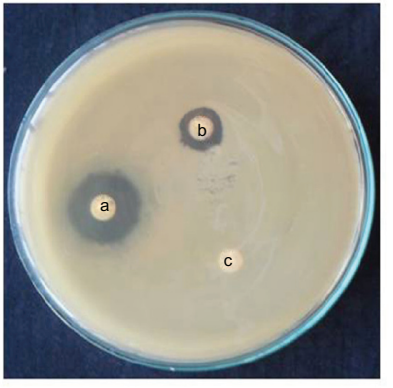

Enterococcus faecalis

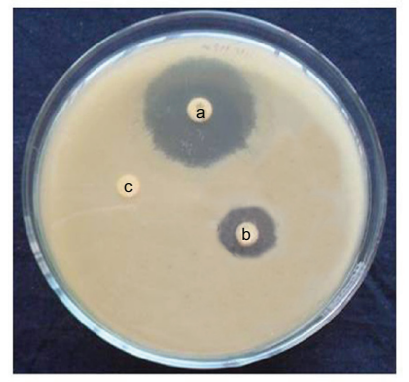

Yersinia enterocolitica

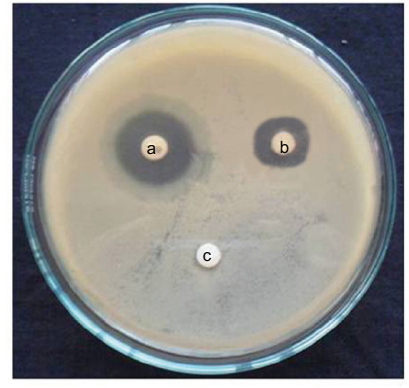

Streptococcus faecalis

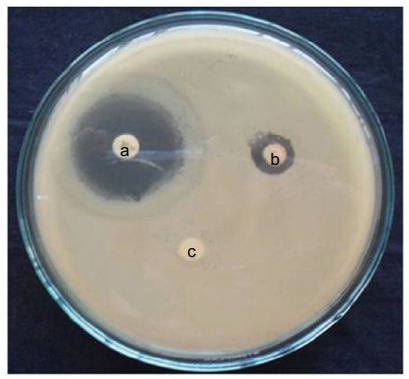

Pseudomonas aeruginosa
Figure I I Activity of gold nanoparticles against different microorganisms depicting zones of inhibition of (A) positive control. (B) gold nanoparticles, and (C) dimethylsulfoxide control.

Embelia ribes, Psoralea corylifolia, Smilax china, Glycyrrhiza glabra, and Andropogon muricatus showed activity against E. coli, P. aeruginosa, S. aureus, and C. albicans, with zones of inhibition measuring less than $8 \mathrm{~mm}$ in diameter. ${ }^{30,33}$ The results of the present study are indicative of pronounced antibacterial effects. They provide an important basis for use

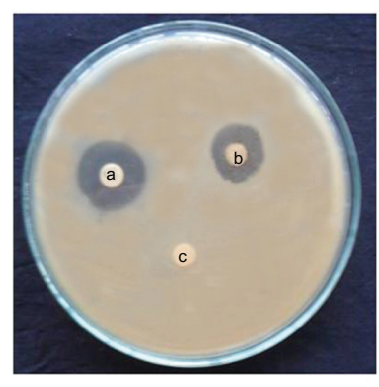

Streptococcus faecalis

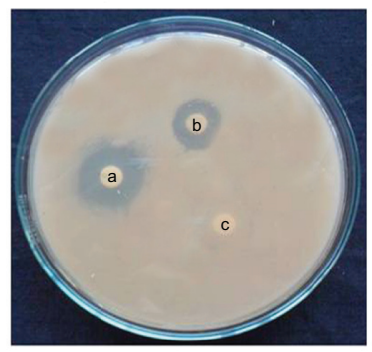

Enterococcus faecalis

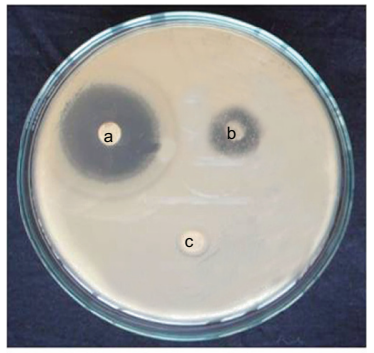

Staphylococcus aureus

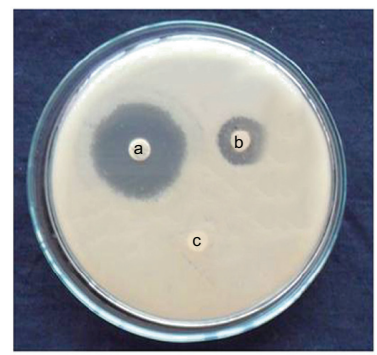

Yersinia enterocolitica
Figure 12 Activity of silver nanoparticles against different micro-organisms depicting zones of inhibition of (A) positive control. (B) silver nanoparticles, and (C) dimethylsulfoxide control. of gold and silver nanoparticles synthesized from the root extract of $T$. decandra in the treatment of human infections associated with the microorganisms used in this study. These might prove to be important leads for the development of new antimicrobial drugs.

\section{Conclusion}

To summarize, we achieved successful green synthesis of gold and silver nanoparticles using $T$. decandra root extract. Silver and gold nanoparticles were synthesized under ambient conditions, and characterization of synthesized nanoparticles was carried out by ultraviolet-visible, Fourier transform infrared, scanning electron and energy dispersive $\mathrm{x}$-ray spectroscopy. It is believed that phytochemicals present in $T$. decandra extract reduce the silver and gold ions into metallic nanoparticles. This strategy reduces the cost of production and the environmental impact. The silver and gold nanoparticles formed showed strong activity against all microorganisms tested.

\section{Acknowledgments}

The authors acknowledge the Botanical Survey of India, TNAU campus, Coimbatore, for identification and authentication of the plant material used in this study. The authors also thank Sri Ramaswamy Memorial University for providing the infrastructure facilities.

\section{Disclosure}

The authors declare no conflicts of interest in this work.

\section{References}

1. Matei A, Cernica I, Cadar O, Roman C, Schiopu V. Synthesis and characterization of ZnO-polymer nanocomposites. Int J Mater Form. 2008;1: 767-770.

2. Kemp MM, Kumar A, Mousa S, et al. Synthesis of gold and silver nanoparticles stabilized with glycosaminoglycans having distinctive biological activities. Biomacromolecules. 2009;10:589-595.

3. Rivas L, Sanchez-Cortes S, Garcia-Ramos JV, Morcillo G. Growth of silver colloidal particles obtained by citrate reduction to increase the Raman enhancement factor. Langmuir. 2001;17:574-577.

4. Zhang Z, Patel RC, Kothari R, Johnson CP, Friberg SE, Aikens PA. Stable silver clusters and nanoparticles prepared in polyacrylate and inverse micellar solutions. J Phys Chem B. 2000;104:1176-1182.

5. Chen W, Cai W, Zhang L, Wang G. Sonochemical processes and formation of gold nanoparticles within pores of mesoporous silica. J Colloid Interface Sci. 2001;238:291-295.

6. Frattini A, Pellegri N, Nicastro D, de Sanctis O. Preparation of amine coated silver nanoparticles using triethylenetetramine. Mater Chem Phys. 2005;94:148-152.

7. Knoll B, Keilmann F. Near-field probing of vibrational absorption for chemical microscopy. Nature. 1999;399:134-137.

8. Sengupta S, Eavarone D, Capila I, Zhao GL, Watson N, Kiziltepe T. Temporal targeting of tumour cells and neovasculature with a nanoscale delivery system. Nature. 2005;436:568-572. 
9. Wiley BJ, Sun Y, Xia Y. Synthesis of silver nanostructures with controlled shapes and properties. Acc Chem Res. 2007;40:1067-1076.

10. Kumar V, Yadav SK. Plant-mediated synthesis of silver and gold nanoparticles and their applications. J Chem Technol Biotechnol. 2009;84:151-157.

11. Chandran SP, Chaudhary M, Pasricha R, Ahmad A, Sastry M. Synthesis of gold nanotriangles and silver nanoparticles using Aloe vera plant extract. Biotechnol Prog. 2006;22:577-583.

12. Mude N, Avinash I, Aniket G, Mahendra R. Synthesis of silver nanoparticles using callus extract of Carica papaya - a first report. J Plant Biochem Biotechnol. 2009;18:83-86.

13. Song JY, Jang HK, Kim BS. Biological synthesis of gold nanoparticles using Magnolia kobus and Diopyros kaki leaf extract. Process Biochem. 2009;44:1133-1138.

14. Lukman AL, Gong B, Marjo CE, Roessner U, Harris AT. J Colloid Interface Sci. 2011;353:433.

15. Singh A, Chaudhary M, Sastry M. Construction of conductive multilayer films of biogenic triangular gold nanoparticles and their application in chemical vapour sensing. Nanotechnology. 2006;17:2399-2405.

16. Shankar SS, Rai A, Ahmad A, Sastry M. Rapid synthesis of Au, Ag, and bimetallic Au core-Ag shell nanoparticles using neem (Azadirachta indica) leaf broth. J Colloid Interface Sci. 2004;75:496-502.

17. Singaravelu G, Arockiamary JS, Ganesh Kumarb V, Govindaraju K. A novel extracellular synthesis of monodisperse gold nanoparticles using marine alga, Sargassumwightii greville. Colloids Surf B Biointerfaces. 2007;57:97-101.

18. Armendariz V, Herrera I, Peralta-Videa J, Jose-Yacaman M, Troiani H, Santiago P. Size controlled gold nanoparticle formation by Avena sativa biomass: use of plants in nanobiotechnology. $J$ Nanopart Res. 2004;6:377-382.

19. Shanker SS, Rai A, Ankamwar B, Singh A, Ahmed A, Sastry M. Biological synthesis of triangular gold nanoprisms. Nat Mater. 2004;3:482.

20. Mukherjee P, Bhattacharya R, Bone N, et al. Potential therapeutic application of gold nanoparticles in B-chronic lymphocytic leukemia (BCLL) enhancing apoptosis. J Nanobiotechnology. 2007;5:4.

21. Chandran SP, Chaudhary M, Pasricha R, Ahmad A, Sastry M. Synthesis of gold nanotriangles and silver nanoparticles using Aloe vera plant extract. Biotechnol Prog. 2006;2:577-583.
22. Kirtikar KR, Basu BD. Indian Medicinal Plants. Allahabad, India: Lalit Mohan Basu Publications; 1983.

23. Geethalakshmi R, Sarada DVL, Marimuthu P. Evaluation of antimicrobial and antioxidant potentials of Trianthema decandra L. Asian J Biotechnol. 2010;2:225-231.

24. Bauer AW, Kirby WMM, Sherris JC, Turck M. Antibiotic susceptibility testing by a standardized single disk method. Am J Clin Pathol. 1966;45:493-496.

25. Link S, El-Sayed MA. Size and temperature dependence of the plasmon absorption of colloidal Au nanoparticles. J Phys Chem. 1999;B103:4212-4217.

26. Geethalakshmi R, Sarada DVL, Ramasamy K. Trianthema decandra L: a review on its phytochemical and pharmacological profile. Int J Eng Sci Technol. 2010;2:976-979.

27. Vijayakumar M, Priya K, Nancy FT, Noorlidah A, Ahmed ABA. Biosynthesis, characterization and anti-bacterial effect of plantmediated silver nanoparticles using Artemisia nilagirica. Indus Crops Prod. 2012;41:235-240.

28. Rai A, Singh A, Ahmad A, Sastry M. Role of halide ions and temperature on the morphology of biologically synthesized gold nanotriangles. Langmuir. 2006;22:736-741.

29. Gardea-Torresdey JL, Gomez E, Peralta-Videa J, et al. Synthesis of gold nanotriangles and silver nanoparticles using Alfalfa sprouts:a natural source for the synthesis of silver nanoparticles. Langmuir. 2003;19:1357-1365.

30. Kaviya S, Santhanalakshmi J, Viswanathan B. Green synthesis of silver nanoparticles using Polyalthia longifolia leaf extract along with D-sorbitol: study of antibacterial activity. J Nanotechnol. 2011:1-5.

31. Morones JR, Elechiguerra LJ, Camacho A, et al. The bactericidal effect of silver nanoparticles. Nanotechnology. 2005;16:2346-2353.

32. Ghosh P, Han G, De M, Kim KC, Rotello MV. Gold nanoparticles in delivery applications. Adv Drug Deliv Rev. 2008;60:1307-1315.

33. Prashanth S, Menaka I, Muthezhilan R, Navin Kumar S. Synthesis of plant-mediated silver nano particles using medicinal plant extract and evaluation of its anti microbial activities. Int J Eng Sci Technol. 2001;3:6235-6250.
International Journal of Nanomedicine

\section{Publish your work in this journal}

The International Journal of Nanomedicine is an international, peerreviewed journal focusing on the application of nanotechnology in diagnostics, therapeutics, and drug delivery systems throughout the biomedical field. This journal is indexed on PubMed Central, MedLine, CAS, SciSearch ${ }^{\circledR}$, Current Contents ${ }^{\circledR} /$ Clinical Medicine,

\section{Dovepress}

Journal Citation Reports/Science Edition, EMBase, Scopus and the Elsevier Bibliographic databases. The manuscript management system is completely online and includes a very quick and fair peer-review system, which is all easy to use. Visit http://www.dovepress.com/ testimonials.php to read real quotes from published authors. 